Helping you helps me: Giving and receiving social support in recovery groups for problem gamblers

\author{
Paul Hutchison ${ }^{1}$ \\ Sharon $\operatorname{Cox}^{2}$ \\ $\&$
}

Daniel Frings ${ }^{2}$

${ }^{1}$ London Metropolitan University, England, UK

${ }^{2}$ London Southbank University, England, UK 


\title{
SOCIAL SUPPORT AND PROBLEM GAMBLING
}

\begin{abstract}
Mutual aid fellowships are the most accessible and widely used treatments for different addictive behaviors including problem gambling, yet how and why such treatments may be effective remains underexplored. The present research investigated the relationships between recovery group identification, social support received and provided to the recovery group, and important recovery-related outcomes among people attending Gamblers Anonymous (GA). Recovery group identification was associated with increased abstinence self-efficacy and decreased perceived risk in gambling-related 'trigger' situations and these relationships were mediated by the perceived provision of social support but not its receipt. The findings suggest that mutual aid fellowships such as GA may be effective in part because they provide opportunities for members to not only receive social support from similar others but also to make a meaningful contribution to other people's recovery through the provision of social support, which can aid their own recovery.
\end{abstract}

Keywords: Group therapy; social identity; social support; addiction; gambling 


\section{SOCIAL SUPPORT AND PROBLEM GAMBLING}

Gambling is recognized internationally as an addictive pastime and problem gambling is linked to high levels of debt, depression, familial breakdown and suicide (Orford, 2010). In the UK, between $0.7 \%$ and $0.9 \%$ of the population exceed recognized annual thresholds for problem gambling (Orford, Wardle, \& Griffiths, 2013). Similar estimates have been reported in the US where approximately $1-3 \%$ of the population meet diagnostic criteria for problem gambling (Kessler et al., 2008) and 6-9\% of young adults experience problems related to gambling, such as increased alcohol consumption and problem drinking (Barnes, Welte, Hoffman, \& Tidwell, 2010). Moreover, although substance use disorders are approximately $3-4 \%$ more prevalent than disorders related to gambling, public funding for substance abuse treatments is approximately 281 times higher than public funding for treatments for problem gambling (Maratto, Bahan, Vander, Linden, \& Whyte, 2014). Thus, there is an urgent need to better understand how and why certain treatments for problem gambling (and other addictions) may be effective, which will assist in the development and enhancement of recovery programs and therapeutic regimes.

\section{Addiction treatments}

Like treatments for other addictions, treatments for problem gambling take various forms including one-to-one counselling, cognitive therapy, cognitive behavioral therapy, drug interventions, and a range of group therapies (Miller, 2013; Petry, 2005; Reilly \& Shaffer, 2007). Of such treatments, group therapies are the most widely used for problem gambling (Schuler et al., 2016). Indeed, group therapies are a common treatment pathway for individuals seeking recovery from a host of different addictions. For example, around $80 \%$ of people aiming to quit drinking will attend at least one group therapy session (Dawson, Grant, Stimson \& Chou, 2006). 


\section{SOCIAL SUPPORT AND PROBLEM GAMBLING}

Gamblers Anonymous (GA) is a mutual aid fellowship based on 12 step principles (Alcoholics Anonymous, 1952). Mutual aid in this context refers to the concept of voluntary reciprocal peer support to address a shared problem, be it illness, maladaptive behavior, substance abuse, or problem gambling (Humphreys, 2006). Like other mutual aid fellowships such as Alcoholics Anonymous (AA) and Narcotics Anonymous (NA), GA provides an environment where problem gamblers can share their experiences with similar others with the aim of helping and supporting each other to maintain their recovery from addiction (see Alcoholics Anonymous, 1952). GA is the most accessible and widely used treatment for people seeking recovery from problem gambling. However, despite its preponderance, evidence for the effectiveness of GA as a stand-alone treatment for problem gambling is scarce and often inconsistent. Indeed, GA is only one of several treatments that problem gamblers may use at any one time. Moreover, GA members differ from problem gamblers with no GA involvement in several ways (Schuler et al., 2016). For example, compared to problem gamblers with no GA involvement, GA members tend to have more severe and longer duration of gambling symptoms, are less likely to have serious substance abuse problems, and are more motivated to seek treatment (Petry, 2005; Schuler et al., 2015; Toneatto, 2008). Such factors - and the paucity of large-scale randomized control trials - make it difficult to draw firm conclusions about the effectiveness of GA as a stand-alone treatment. Nevertheless, a review of studies published between 2002 and 2015 (Schuler et al., 2016) confirmed that GA involvement is associated with increased abstinence (Oei \& Gordon, 2008), increased readiness for change (Gomes \& Pascual-Leone, 2009), and improved coping skills (Petry, Litt, Kadden, \& Ledgerwood, 2007), especially when used in conjunction with other treatments. 


\section{SOCIAL SUPPORT AND PROBLEM GAMBLING}

Of particular relevance to the aims of present study is the lack of research on how and why mutual aid fellowships such as GA may be effective. Indeed, despite the preponderance of theoretical arguments and hypotheses about the therapeutic factors in group therapy treatments (e.g., Bernard et al., 2008; Yalom \& Leszcz, 2005), empirical studies are few and far between. The present research goes some way towards addressing this limitation. Drawing on theory and research in the addiction recovery, social identity, and social support literatures, we propose that mutual aid fellowships such as GA may be an effective part of recovery to the extent that they provide a basis for group members to not only receive social support from similar others, but also to make a meaningful contribution to other people's recovery by providing social support.

\section{Social identities and social support}

An increasing body of research suggests that group memberships and the social identities that people derive from them (Hogg \& Abrams, 1988; Tajfel \& Turner, 1979) can benefit health and wellbeing (e.g., Haslam, Jetten, Cruwys, Dingle, \& Haslam, 2018; Jetten, Haslam \& Haslam, 2011). For example, Cruwys et al. (2014) found that identification with a community recreation group (Study 1) and a clinical psychotherapy group (Study 2) positively predicted recovery from depression. Along similar lines, group identification has been shown to predict reduced stress among prison guards (Sani, Magrin, Scrigaro, \& McCollumm, 2010), bomb disposal experts (Haslam, O’Brien, Jetten, Vormedal, \& Penna, 2005, Study 1) and people recovering from heart surgery (Haslam et al., 2005, Study 2) and cancer (Swartzman, Sani, \& Munro, 2016). Such research suggests that group memberships may be conducive to positive health and wellbeing because they provide the basis for individuals to receive - or feel that they can receive - social support from similar others (Avanzi, Schuh, 


\section{SOCIAL SUPPORT AND PROBLEM GAMBLING}

Fraccaroli, \& van Dijk, 2015). Indeed, there is evidence that the feeling of being socially supported mediates the positive effect that group identification has on important health and wellbeing-related outcomes (Haslam et al., 2005).

The positive effects of belonging to and identifying with social groups has increasingly been acknowledged in theory and research on addiction recovery (Best et al., 2016; Bond, Kaskutas, \& Weisner, 2003; Buckingham, Frings, \& Albery, 2013; Haslam et al., 2018). Theoretical models such as the Social Identity Model of Cessation Maintenance (Frings \& Albery, 2016) and the Social Identity Model of Recovery (Best et al., 2016) propose that mutual aid fellowships such as GA may facilitate recovery from addiction in part because they help to foster meaningful social identifications (e.g., 'us recovering addicts') that help group members structure and make sense of their experiences. Such identifications also provide members with an important sense of perceived social support (Best et al., 2016; Buckingham et al., 2013). In an addiction recovery context this may take the form of informational support, emotional support, or practical assistance. Indeed, there is evidence from research in different addiction domains that the receipt of abstinence-specific social support and its perceived availability predict important recovery-related outcomes such as improved abstinence self-efficacy and reduced risk of (re)lapse (e.g., Beattie \& Longabaugh, 1999; Dingle, Cruwys, \& Frings, 2015; Frings et al., 2016).

Although the literature on the benefits of receiving social support (inside and outside of the addiction domain) is relatively well-developed, there has been little empirical exploration of the potential benefits to one's own recovery of providing support to other people. This is surprising given that an important feature of mutual aid fellowships is the concept of 'service' - once members have ceased their addictive behavior and maintained this cessation for some time, they are encouraged to become 


\section{SOCIAL SUPPORT AND PROBLEM GAMBLING}

a 'sponsor' to provide help and support to those newer to recovery (Alcoholics Anonymous, 1952). In doing so, the former come to see themselves as an important source of influence and support for newer members, which benefits both parties (Pagano et al., 2004; Weinstein \& Ryan, 2010; Yalom \& Leszcz, 2005). This is in line with one of the fundamental principles in the 12 step programs that underpin mutual aid fellowships, according to which 'You can't keep it unless you give it away' (Alcoholics Anonymous, 1952). In other words, personal recovery can only be maintained by shifting one's focus from self to others and actively supporting them in their recovery. These ideas are consistent with Yalom and Leszcz's (2005) assertion that 'altruism' - i.e., the sense of having selflessly helped other people through personally sharing and giving - is one of several therapeutic factors in small group therapy that benefit both the helper and those being helped. They also concur with Riessman's (1976) 'helper therapy principle', according to which those who help others indirectly help themselves.

Support for these assumptions comes primarily from research in nonaddictions domains showing that helping (e.g., through volunteering) positively predicts important health and wellbeing-related outcomes (e.g., Brown, Nesse, Vinokur, \& Smith, 2003; Greenfield \& Marks, 2004; Weinstein \& Ryan, 2010). Only a few studies have assessed how helping might contribute positively to the helper's recovery from addiction. Zemore, Kaskutas, and Ammon (2004) found that the amount of time that recovering alcoholics spent engaged in community-related helping initiatives positively predicted the length of their own sobriety (see also Crape, Latkin, Laris, \& Knowlton, 2002). Similarly, Pagano et al. (2004) found that active helping at AA meetings was associated with greater abstinence at 10-year follow up, independent of the number of AA meetings attended. These findings 


\section{SOCIAL SUPPORT AND PROBLEM GAMBLING}

provide some support for the proposed mutual benefits of providing support to other people in addiction recovery treatments and the assumption in the mutual aid fellowship literature that "helping you helps me" (Kelly et al., 2009, p. 241). However, to our knowledge, no previous research has examined how helping people in recovery from problem gambling might contribute positively to the helper's recovery.

\section{The present research}

The present research aimed to develop and extend previous research on the benefits to recovery of not only receiving social support but also of providing support to other people in their recovery. Problem gamblers attending a GA mutual aid fellowship in the UK completed measures of recovery group identification, social support received and provided to the recovery group, and important recovery-related outcomes: abstinence self-efficacy and perceived risk in gambling-related 'trigger' situations. A considerable body of theory and research has highlighted the important role of abstinence self-efficacy and risk perception/management in recovery from addiction (e.g., Best et al., 2016; Buckingham et al., 2013; Carbonari \& DiClemente, 2000; DiClemente, Fairhurst, \& Piotrowski, 1995; Kelly et al., 2012). Self-efficacy in the present context refers to the belief that one can (or cannot) achieve one's aims or goals, which can be specific (e.g., related to particular behavior) or more generic (see Bandura, 1977). Buckingham et al. (2013) found that abstinence self-efficacy was positively associated with actual abstinence among people attending AA and NA. Similarly, perceived risk in the present context refers to the extent to which different addiction-related 'trigger' situations (e.g., a problem gambler passing a betting shop) are perceived as presenting a risk to one's recovery at this point in time. Previous research suggests that a feeling of confidence in one's ability to cope effectively in 


\section{SOCIAL SUPPORT AND PROBLEM GAMBLING}

such situations (i.e., perceiving them as presenting little or no risk) is inversely related to the probability of (re)lapse (e.g., Buckingham et al., 2013; Marlatt \& George, 1984).

Drawing on this previous work and theory and research in the addiction recovery, social identity, and social support literatures, we propose that mutual aid fellowships such as GA may be effective to the extent that they foster a common identity for people seeking recovery from addiction (Best et al., 2016; Dingle et al., 2015; Frings \& Albery, 2016; Haslam et al., 2018) and, in doing so, provide the opportunity for their members to not only receive social support from similar others but also to make a meaningful contribution to other people's recovery by providing social support, which in turn helps the former to actively maintain their own recovery (Best et al., 2016). Reflecting this, we tested a model in which the perceived amount of support received and provided to the recovery group were conceptualized as mediators of the proposed relationship between recovery group identification and both abstinence self-efficacy and perceived risk in gambling-related 'trigger' situations. More specifically, it was predicted that recovery group identification would be associated with more perceived support received and provided to the recovery group, which in turn was expected to predict more abstinence self-efficacy and less perceived risk.

\section{Method}

\section{Participants}

Ethical approval was received from London South Bank University. The sample consisted of 44 problem gamblers attending an open GA mutual aid fellowship in South East England, UK. ${ }^{1}$ Forty-one were male and 3 were female. Ages ranged from 23 to 84 years $(M=49.72 ; S D=17.29)$. All participants were 


\section{SOCIAL SUPPORT AND PROBLEM GAMBLING}

British nationals. The group holds weekly meetings lasting approximately 1-2 hours which are typically attended by approximately 10-30 members and are chaired by relatively experienced members who also act as sponsors. Sixteen participants identified themselves as sponsors. Thirty-nine participants indicated attending weekly and five indicated attending monthly. All participants had attended at least one group meeting in the month prior to completing the questionnaire. Gender and frequency of attendance at GA meetings were unrelated to any other variables but were included as covariates in subsequent analyses to remain consistent with previous research in this domain. Relationships between participants' age, whether they acted as a sponsor or not, and the variables of primary interest are described below.

\section{Materials and Procedure}

To maximize recruitment the same GA fellowship was visited on three consecutive weeks by the same researcher who invited members to participate in a study on "their thoughts and feelings about the group and their recovery". Those who agreed to participate received a questionnaire containing all instructions and measures which were completed individually and in private before the meeting started. This was intended to reduce the likelihood that responses would be unduly influenced by the meeting that participants had attended that day. Thirty five participants completed the questionnaire in the first week of data collection, six in the second week, and three in the third week. Each participant completed the questionnaire once only: on the second and third weeks of data collection participants were asked to confirm that they had not previously completed the questionnaire. Once the questionnaires were completed, participants were thanked and debriefed.

\section{Measures}




\section{SOCIAL SUPPORT AND PROBLEM GAMBLING}

Recovery group identification. Identification with the recovery group was assessed using the 4-item group identification measure developed by Doosje, Ellemers and Spears (1995) which has been widely used to assess identification with a host of different social and organizational groups, including AA and NA mutual aid fellowships (e.g., Buckingham et al., 2013). The items were modified to refer specifically to the recovery group but were otherwise identical to those in the original measure. Example items are: 'I identify with other members of the recovery group', 'I see myself as a member of this recovery group', and 'I feel strong ties with other members of this recovery group'. Responses were recorded on a scale ranging from 1 (do not agree at all) to 7 (agree completely). A mean score was calculated, with higher scores indicating stronger recovery group identification. Doosje et al. (1995) reported a Cronbach's alpha of .83 and in the present sample it was .85 .

Support received from the recovery group. The amount of support participants believed they received from the recovery group was assessed using a modified version of the Multidimensional Scale of Social Support (MSSS: Zimet, Dhalem, Zimet, \& Farley, 1988). The MSSS consists of 12 items assessing the perceived amount of social support received from different groups and individuals (e.g., family, friends and significant others). For present purposes we removed the four items that referred specifically to support received from a particular individual (e.g. "a special person") and modified the remaining eight items to refer specifically to the recovery group. Example items are: 'The group really tries to help me', 'I can count on the group when things go wrong', and 'I can talk about my problems with the group'. Responses were recorded on a scale ranging from 1 (strongly disagree) to 5 (strongly agree) and were averaged to form a single score, with higher scores indicating more support received from the recovery group. The original version of the 


\section{SOCIAL SUPPORT AND PROBLEM GAMBLING}

MSSS has shown good validity and internal consistency with different samples (Dahlem, Zimet, \& Walker, 1991; Zimit et al., 1988; Zimet, Powell, Farley, Werkman \& Berkoff, 1999). Zimit et al. (1988) reported a Cronbach's alpha of .88 for the MSSS and it was .95 for the version used in the present study.

Support provided to the recovery group. The same eight MSSS items were adapted to assess the amount of support participants believed they provided to the recovery group. Example items are: 'I really try to help the group', 'The group can count on me when things go wrong', and 'Group members can talk about their problems to me'. Responses were recorded on the same 5-point scale described above and were combined to form a single score, with higher scores indicating more perceived support provided to the recovery group. Cronbach's alpha for this measure was .96.

Abstinence self-efficacy. This was assessed using the 4-item measure developed by Buckingham et al. (2013). One item was modified to refer specifically to gambling behavior rather than alcohol or drug-related behavior as in the original measure, otherwise the items were the same as those in the original measure. Example items are: 'I think I can achieve recovery', 'It is unlikely I will remain gambling-free' (reverse scored)', and 'I can remain abstinent'. Responses were recorded on a 7-point scale ranging from 1 (strongly disagree) to 7 (strongly agree) and were averaged to form a single score, with higher scores indicating more abstinence self-efficacy.

Buckingham et al. (2013) reported Cronbach's alphas of .82 (Study 1) and .73 (Study 2) and in the present sample it was .94 .

Perceived risk. Participants rated the extent to which each of five gamblingrelated situations would, if encountered, be perceived as a risk to their recovery at this point in time. The situations described were modelled on those identified in previous 


\section{SOCIAL SUPPORT AND PROBLEM GAMBLING}

research as posing a risk to recovering addicts' sense of control or abstinence (Buckingham et al., 2013; Marlatt \& George, 1984). Example situations are: 'Going out with friends who like to gamble', 'Passing a betting shop', and 'Seeing a gambling advert on TV'. Responses were recorded on a scale ranging from 1 (not at all risky) to 10 (very risky) and were combined to form a single score, with higher scores indicating more perceived risk. Cronbach's alpha for this measure was .94 .

\section{Results}

\section{Preliminary analysis}

Table 1 displays the means and standard deviations for the measures as well as the relationships between the variables. Recovery group identification was positively associated with the perceived amount of support received and provided to the recovery group and abstinence self-efficacy, and negatively associated with perceived risk. Support received and support provided were both positively associated with abstinence self-efficacy and negatively associated with perceived risk. ${ }^{2}$

In addition, although not displayed in Table 1, age was positively associated with support received, $r(44)=.38, p=.011$, support provided, $r(44)=.53, p<.001$, and abstinence self-efficacy, $r(44)=.41, p=.005$, and was negatively associated with perceived risk, $r(44)=-.48, p=.001$. Finally, one-way ANOVA confirmed that, compared to regular members, sponsors scored higher on support provided $(M s=$ 4.37, 3.36, SDs $=1.09,0.85), F(1,43)=5.56, p=.023$, and abstinence self-efficacy $(M s=5.70,4.41, S D s=1.59,1.53), F(1,43)=7.04, p=.011$, and lower on perceived $\operatorname{risk}(M s=2.52,4.18, S D s=2.47,2.44), F(1,43)=4.67, p=.037$. Thus, as well as age, gender, and frequency of attendance at GA meetings, whether participants acted as a sponsor or not was controlled for in the analyses described below. ${ }^{3}$

\section{Regression analysis}




\section{SOCIAL SUPPORT AND PROBLEM GAMBLING}

Multiple linear regression analysis was used to examine the extent to which recovery group identification and support received and provided to the recovery group predict abstinence self-efficacy and perceived risk. The regression equation was significant when abstinence self-efficacy was the outcome, $F(7,36)=19.39, p<.001$, $R^{2}=.79$. Recovery group identification, $B=.34, S E=.12, t=2.83, p=.007$, and support provided, $B=.44, S E=.15, t=2.91, p=.006$, were both positively associated with abstinence self-efficacy whereas support received was not, $B=.18$, $S E=.12, t=1.44, p=.15$. The regression equation was also significant when perceived risk was the outcome, $F(7,36)=7.77, p<.001, R^{2}=.60$. However, support provided, $B=-.37, S E=.21, t=-1.79, p=.07$, support received, $B=-.10, S E=.17, t$ $=-0.61, p=.55$, and recovery group identification, $B=-.28, S E=.16, t=-1.67, p=$ .11 , did not uniquely predict perceived risk.

\section{Mediation analyses}

To test the prediction that the relationships between recovery group identification and both abstinence self-efficacy and perceived risk are mediated by the perceived amount of support received and provided to the recovery group we used the Process Macro for SPSS (Hayes, 2017), which uses bootstrap techniques to estimate the total and direct effects of a predictor variable on an outcome variable as well as the indirect effects through one or more mediator variables. This method has the advantage of greater statistical power without assuming multivariate normality in the sampling distribution and is recommended over alternative methods when the sample size is relatively small (Hayes, 2017). An indirect (mediated) effect is evident if the bias-corrected $95 \%$ confidence interval $(B C C I)$ does not include zero. The analyses described below are based on 5,000 bootstrapped resamples. Scores were standardized prior to analysis. 


\section{SOCIAL SUPPORT AND PROBLEM GAMBLING}

In this analysis, support received and support provided were investigated as mediators of the positive relationship between recovery group identification and abstinence self-efficacy (Hayes, 2017, Model 4). As shown in Figure 1, the total effect of recovery group identification on abstinence self-efficacy was significant, $B=$ $.72, t=6.88, S E=.10, p<.001$, as was the direct effect, $B=.34, t=2.84, S E=.12, p$ $=.008$. The total indirect effect through both support received and support provided was also significant, $P E=.38, S E=.12, B C C I: L L=.175, U L=.626$, as was the specific indirect effect through support provided, $P E=.27, S E=.11, B C C I: L L=$ $.073, U L=.499$, whereas the specific indirect effect through support received was not significant, $P E=.10, S E=.09, B C C I: L L=-.023, U L=.369$. This confirms that the positive relationship between recovery group identification and abstinence selfefficacy is mediated by the perceived amount of support provided to the recovery group and not the perceived amount of support received from the group.

The same analysis was conducted on the perceived risk scores. The total effect of recovery group identification on perceived risk was significant, $B=-.57, \mathrm{t}=-4.56$, $S E=.12, p<.001$, whereas the direct effect was not significant, $B=-.28, \mathrm{t}=-1.67$, $S E=.16, p=.10$. The total indirect effect through both support received and support provided was significant, $P E=-.29, S E=.14, B C C I: L L=-.576, U L=-.036$, as was the specific indirect effect through support provided, $P E=-.23, S E=.14, B C C I: L L$ $=-.569, U L=-.002$, whereas the specific indirect effect through support received was not significant, $P E=-.06, S E=.09, B C C I: L L=-.253, U L=.131$. This confirms that the negative relationship between recovery group identification and perceived risk is mediated by the perceived amount of support provided to the recovery group but not its receipt.

\section{Discussion}




\section{SOCIAL SUPPORT AND PROBLEM GAMBLING}

Mutual aid fellowships are the most accessible and widely used treatments for people recovering from addictions, including gambling addiction. Theoretical models such as the Social Identity Model of Cessation Maintenance (Frings \& Albery, 2016) and the Social Identity Model of Recovery (Best et al., 2016) maintain that fellowships such as GA are effective in part because they foster meaningful social identifications among their members that help them to structure and make sense of their experiences and which, over time, supersede previous identifications defined by addiction-related thoughts and behaviors (Best et al., 2016). Mutual aid fellowships also provide an important source of social support for their members which is known to aid abstinence and recovery from different addictions (e.g., Best et al., 2016; Dingle et al., 2015; Frings \& Albery, 2016). The present research provided a further test of these assumptions with a sample of problem gamblers attending a GA mutual aid fellowship. It also investigated the potential benefits to recovery of providing support to other members of the recovery group. This is important because despite the preponderance of theoretical assumptions and hypotheses about the mutually beneficial role of helping other people in group therapy contexts (e.g., Riessman, 1976; Yalom \& Leszcz, 2005), empirical studies are relatively scare and, to our knowledge, none have been conducted in the context of recovery from problem gambling.

The results concur with recent findings in the literature on addiction recovery, demonstrating that identification with a recovery group predicts more perceived support received from the group, more abstinence self-efficacy, and less perceived risk in gambling-related 'trigger' situations (e.g., Buckingham et al., 2013; Frings et al., 2016; see also Haslam et al., 2018). Going beyond previous research, the present findings additionally show that those who identified more with the recovery group 


\section{SOCIAL SUPPORT AND PROBLEM GAMBLING}

indicated providing more support to other group members, which in turn was associated with more abstinence self-efficacy and less perceived risk. Furthermore, the relationships between recovery group identification and both abstinence selfefficacy and perceived risk were mediated by the perceived provision of social support and not its receipt, and these effects were independent of whether respondents acted as a sponsor to those newer to recovery (i.e., when sponsorship was controlled for). These findings are consistent with one of the key assumptions in the 12 step and mutual aid fellowship literatures - that actively supporting other people in recovery is beneficial to both the recipient and provider, making it a mutually beneficial process. To this extent, the findings provide empirical support for Yalom and Leszcz's (2005) much repeated but rarely investigated assertion that 'altruism' is an important therapeutic factor in small group therapy.

From a theoretical point of view the present findings are important because they add weight to the idea that social support is an 'active ingredient' of mutual aid fellowships (Moos, 2007). More importantly, the results extend understanding of how and why mutual aid fellowships such as GA (and group therapies more generally) may be effective. In particular, and from a practical point of view, the results point to the potential benefits of not only being or feeling supported by similar others during recovery, but also of actively helping others in their recovery. Indeed, the findings show that although the perceived receipt and provision of support were both associated with more abstinence self-efficacy and less perceived risk in gamblingrelated 'trigger' situations, the relationship between recovery group identification and both outcome variables was explained by the perceived amount of support provided to the recovery group and not its receipt. Of course, this is not to say that receiving social support is unimportant for recovery. Indeed, when support provided to the 


\section{SOCIAL SUPPORT AND PROBLEM GAMBLING}

recovery group was not included as a mediator in the regression model (i.e., when it was not controlled for), the indirect path from recovery group identification to abstinence self-efficacy through support received was significant. ${ }^{4}$ However, when support received and support provided were simultaneously included as mediators in the model, the provision of social support had a more pronounced effect on important recovery-related outcomes than its receipt.

The present results are in line with findings from previous research in nonaddiction (e.g., Brown et al., 2003; Steffens, Jetten, Haslam, Cruwys, \& Haslam, 2016) and addiction recovery domains (e.g., Crape et al., 2002; Zemore et al., 2004; Pagano et al., 2004) suggesting that helping others aids both the recipient and the provider. Extending previous research, our findings additionally show that recovery group identification predicts the amount of support that group members feel they provide to others, which in turn predicts more desirable recovery-related outcomes. This supports the idea that mutual aid fellowships are effective to the extent that they foster a common identity among people facing similar problems and, in doing so, provide a context where group members can not only receive social support from similar others but can also contribute to other people's recovery by providing social support, which helps the former to actively maintain their own recovery. This is in line with Best et al.'s (2016) conceptualization of addiction recovery as a socially mediated process, facilitated by the internalization of a recovery-related identity and maintained through the enactment of recovery-related behaviors. It also concurs with theory and research in non-addiction domains suggesting that when a shared group identity is salient, people are more likely to support fellow ingroup members and feel that they can receive support from others in return (Haslam et al., 2018; Hogg \& Abrams, 1988; Jetten et al., 2011). 


\section{SOCIAL SUPPORT AND PROBLEM GAMBLING}

Although the results are broadly in line with predictions derived from the addiction recovery, social identity, and social support literatures, there are limitations with the present study that future research should aim to address. Firstly, the findings are based on cross-sectional survey data which makes it difficult to draw firm conclusions about causality. Future research should be conducted longitudinally to allow stronger inferences about the relationships between the variables examined in the present study to be established. Such analyses would also allow investigation of the stages through which recovering addicts' identities and identity-related behaviors develop and change as they transition from an identity defined primarily by addictionrelated behavior to a shared recovery-focused identity based on mutual understanding and support (Best et al., 2016). Indeed, 'altruism' (Yalom \& Leszcz, 2005) is often conceptualized as a relatively advanced therapeutic factor in small group therapy, in that it tends to be perceived at later stages of group formation (Kivlighan \& Goldfine, 1991; Kivlighan \& Mullison, 1988; Robinson, 2012). Longitudinal research would help to identify when altruism develops and influences other recovery-focused outcomes such as those examined in the present research.

A second limitation concerns the measures used in the present study. Despite being similar/identical to those used in previous research, the measures used in the present study included items that were modified to refer specifically to the present gambling addiction recovery context. In addition, we removed some items from the MSSS to make it more relevant to the present recovery group context. Such modifications inevitably raise concerns about the measures' validity. This limitation, combined with the relatively small number of problem gamblers available to participate in the present study, means that conclusions must be evaluated accordingly and further research using validated measures and larger samples is required to 


\section{SOCIAL SUPPORT AND PROBLEM GAMBLING}

establish the robustness of the findings. Larger samples would also allow more sophisticated analyses (e.g. multi-level modelling) to be performed to help account for potential unobserved group characteristics associated the different treatment sessions that participants attend (Baldwin, Murray, \& Shadish, 2005).

A related limitation is that no direct measures of abstinence or gamblingrelated behavior were included in the present study. It may be that the self-reported self-efficacy and perceived risk scores observed in the present study do not correspond to actual abstinence or gambling-related behavior. Although confidence that the present results do have relevance to actual abstinence and gambling-related behavior is buttressed by findings from research demonstrating links between recovery-related outcomes like those assessed in the present study and actual abstinence and (re)lapse rates (e.g., Buckingham et al., 2013; Carbonari \& DiClemente, 2000; Stephens, Wertz, \& Roffman, 1995), future research should assess actual abstinence and (re)lapse rates to provide a better understanding of their relationship with the variables explored in the present study.

Another limitation concerns the potential for socially desirable responding. This may be a concern especially in research conducted in the context of group therapies where members may feel implicit or explicit pressure to present the group in a positive light. Group members may also exaggerate the extent of their own contribution to the group. It is also possible that those members more prone to exaggerate their estimates of their own contribution to the group may be more likely to similarly misrepresent their own self-efficacy and risk perceptions, which may lead to artefactual associations between the variables (Zenmore \& Pagano, 2008). Thus it is difficult to conclude with certainty that the associations between the variables in the present were not (at least in part) an artefact of socially desirable responding. This is 


\section{SOCIAL SUPPORT AND PROBLEM GAMBLING}

despite the fact that the measures were completed in private and participants were assured that their responses would remain confidential and anonymous. With this in mind, future research should include appropriate measures to help identify (or control for) potentially biased responding.

Future research should also assess other factors known to predict important recovery-related outcomes like those assessed in the present study. This includes the duration of attendance at fellowship meetings, whether other forms of treatment are used in conjunction with fellowship attendance, and factors such as the perceived cohesiveness and climate of the treatment group, all of which have been shown to predict treatment satisfaction and success (see Bernard et al., 2008; Oei \& Gordon, 2008; Schuler et al., 2016). In addition, no distinctions were made in the present study between the types of support that members received or provided to the group. It may be that different types of support influence treatment satisfaction and success in different ways at different stages of group recovery (Robinson, 2012; Zenmore, Kaskutas, \& Ammon, 2004). Future research is required to explore these possibilities. Finally, due to restrictions agreed prior to data collection we were unable to gather information about the participants' mental health or current or past substance use or dependence. Thus, our findings are likely to be an incomplete clinical picture of those who participated in the study and of GA members and problem gamblers more generally. Indeed, substance dependence and psychiatric disorders are highly prevalent among problem gamblers (Rodriguez-Monguio, Errea \& Volberg, 2017) and such comorbidities may impact on individuals' personal experiences of group therapy treatments, both practically (e.g. in terms of attendance and retention rates) and psychologically (e.g., in terms of factors such as engagement and emotional 


\section{SOCIAL SUPPORT AND PROBLEM GAMBLING}

connectivity). Whether the present results stand up to replication in groups consisting of members with comorbid clinical needs should be a direction of future research.

\section{Conclusion}

The present study investigated the relationships between important recoveryrelated outcomes and both the perceived receipt and provision of social support among problem gamblers attending a GA mutual aid fellowship. The results lend further weight to the idea that group treatments such as GA are effective in part because they provide an important source of social support for their members (Best et al., 2016; Buckingham et al., 2013; Frings \& Albery, 2013; Haslam et al., 2018). Going beyond previous research, the results additionally show that providing support to other people may be even more beneficial (see also Steffens et al., 2016). Such findings have important clinical implications and treatment providers should aim to capitalize on them through initiatives aimed at fostering identity-based bonds among recovering addicts (see also Best et al., 2016) and provision of opportunities for them to not only receive social support during and after treatment but also to actively participate in mutually supportive and pro-social networks with other recovering addicts (e.g., through formal or informal peer mentoring or outreach work), which can help sustain their own recovery-focused identity and, ultimately, their abstinence and recovery. Of course, this is not to say that other treatments for problem gambling (or other addictions) should be abandoned. Our results suggest that regardless of the different treatment(s) that individuals may seek or receive to aid their recovery, initiatives aimed at strengthening social bonds among people facing similar problems and providing opportunities to contribute to their recovery may help to optimize treatment and ongoing recovery. 


\section{SOCIAL SUPPORT AND PROBLEM GAMBLING}

\section{References}

Alcoholics Anonymous (1952). Twelve steps and twelve traditions. New York:

Alcoholics Anonymous World Services.

Avanzi, L., Schuh, S. C., Fraccaroli, F., \& van Dick, R. (2015). Why does organizational identification relate to reduced employee burnout? The mediating influence of social support and collective efficacy. Work and Stress, 29, 1-10.

Baldwin, S. A., Murray, D. M., \& Shadish, W. R. (2005). Empirically supported treatments or Type I errors? Problems with the analysis of data from groupadministered treatments. Journal of Consulting and Clinical Psychology, 73, 924-935.

Barnes, G. M., Welte, J. W., Hoffman, J. H., \& Tidwell, M. C. O. (2010).

Comparisons of gambling and alcohol use among college students and noncollege young people in the United States. Journal of American College Health, $58,443-452$.

Bandura, A. (1997). Self-efficacy: toward a unifying theory of behavioral change, Psychology Review, 84, 191-215.

Beattie, M. \& Longabaugh, R. (1999). General and alcohol-specific support following treatment, Addictive Behaviours, 24, 593-606.

Bernard, H., Burlingame, G., Flores, P., Greene, L., Joyce, A., Kobos, J. C., ... \& Feirman, D. (2008). Clinical practice guidelines for group psychotherapy. International Journal of Group Psychotherapy, 58, 455-542.

Best, D., Beckwith, M., Haslam, C., Haslam, A.S., Jetten, J., Mawson, E., \& Lubman, D. I. (2016). Overcoming alcohol and other drug addiction as a process of social identity transition: The Social Identity Model of Recovery (SIMOR). Addiction Research and Theory, 24, 111-123. 


\section{SOCIAL SUPPORT AND PROBLEM GAMBLING}

Bond, J., Kaskutas, L. A., \& Weisner, C. (2003). The persistent influence of social networks and alcoholics anonymous on abstinence. Journal of Studies on Alcohol, 64, 579-588.

Brown, S., Nesse, R. M., Vinokur, A. D., \& Smith, D. M. (2003). Providing social support may be more beneficial than receiving it: Results from a prospective study of mortality. Psychological Science, 14, 320-327.

Buckingham, S. A., Frings, D., \& Albery, I. P. (2013). Group membership and social identity in addiction recovery. Psychology of Addictive Behaviors, 27, 11321140.

Caldwell, P. E., \& Cutter, H. S. G. (1998). Alcoholics Anonymous affiliation during early recovery. Journal of Substance Abuse Treatment, 15, 221-228.

Carbonari, J. P., \& DiClemente, C. C. (2000). Using transtheoretical model profiles to differentiate levels of alcohol abstinence success. Journal of Consulting and Clinical Psychology, 68, 810-817.

Cohen, J., Cohen, P.,West, S. G., \& Aiken, L. S. (2003). Applied multiple regression/correlation analysis for the behavioral sciences (3rd ed.). Mahwah, NJ: Lawrence Erlbaum.

Crape, B. L., Latkin, C. A., Laris, A. S., \& Knowlton, A. R. (2002). The effects of sponsorship in 12-step treatment of injection drug users. Drug and Alcohol Dependence, 65, 291-301.

Cruwys, T., Haslam, S. A., Dingle, G. A., Jetten, J., Hornsey, M. J., Chong, E. D., \& Oei, T. P. (2014). Feeling connected again: Interventions that increase social identification reduce depression symptoms in community and clinical settings. Journal of Affective Disorders, 159, 139-146. 


\section{SOCIAL SUPPORT AND PROBLEM GAMBLING}

Dahlem, N. W., Zimet, G. D., \& Walker, R. R. (1991). The multidimensional scale of perceived social support: a confirmation study. Journal of Clinical Psychology, 47, 756-761.

Dawson, D. A., Grant, B. F., Stinson, F. S., \& Chou, P. S. (2006). Estimating the effect of help-seeking on achieving recovery from alcohol dependence. Addiction, 101, 824-834.

DiClemente, C. C., Fairhurst, S. K., \& Piotrowski, N. A. (1995). Self-efficacy and addictive behaviors. In J. E. Maddux (Ed.), Self-efficacy, adaptation, and adjustment: Theory, research, and application (pp. 109-141). New York: Plenum.

Dingle, G. A., Cruwys, T., \& Frings, D. (2015). Social identities as pathways into and out of addiction. Frontiers in Psychology, 6, 1795.

Doosje, B., Ellemers, N., \& Spears, R. (1995). Perceived intragroup variability as a function of group status and identification. Journal of Experimental Social Psychology, 31, 410-436.

Frings, D., \& Albery, I.P. (2016). The Social Identity Model of Cessation Maintenance. In S.A. Buckingham \& D. Best (Eds). Addiction, behavioural change and social identity. (pp. 116-137). London: Routledge.

Greenfield, E. A., \& Marks, N. F. (2004). Formal volunteering as a protective factor for older adults' psychological wellbeing. The Journals of Gerontology Series B: Psychological Sciences and Social Sciences, 59, 258-264

Gomes, K., \& Pascual-Leone, A. (2009). Primed for change: Facilitating factors in problem gambling treatment. Journal of Gambling Studies, 25, 1-17.

Haslam, C., Jetten, J., Cruwys, T., Dingle, G., \& Haslam, A. (2018). The new psychology of health: Unlocking the social cure. London: Routledge. 


\section{SOCIAL SUPPORT AND PROBLEM GAMBLING}

Haslam, S. A., O’Brien, A., Jetten, J., Vormedal, K., \& Penna, S. (2005). Taking the strain: Social identity, social support, and the experience of stress. British Journal of Social Psychology, 44, 355-370.

Haslam, S. A., \& Reicher, S. (2006). Stressing the group: social identity and the unfolding dynamics of responses to stress. Journal of Applied Psychology, 91, $1037-1052$

Hayes, A. F. (2017). Introduction to mediation, moderation, and conditional process analysis: A regression-based approach. New York: Guilford Press.

Hogg, M. A., \& Abrams, D. (1988). Social identifications. London: Routledge

Humphreys, K. (2006). The trials of Alcoholics Anonymous. Addiction, 101, 617618.

Jetten, J., Haslam, C., \& Haslam, S. A. (Eds.). (2011). The social cure: Identity, health and well-being. Hove, England: Psychology Press.

Kelly, J. F., Magill, M., \& Stout, R. L. (2009). How do people recover from alcohol dependence? A systematic review of the research on mechanisms of behavior change in Alcoholics Anonymous. Addiction Research \& Theory, 17, 236-259.

Kessler, R. C., Hwang, I., LaBrie, R., Petukhova, M., Sampson, N. A., Winters, K. C., \& Shaffer, H. J. (2008). DSM-IV pathological gambling in the National Comorbidity Survey Replication. Psychological Medicine, 38, 1351-1360.

Kivlighan D. M., Jr., \& Goldfine, D. C. (1991). Endorsement of therapeutic factors as a function of stage of group development and participant interpersonal attitudes. Journal of Counseling Psychology, 38, 150-158.

Kivlighan, D. M., Jr., \& Mullison, D. (1988). Participants' perception of therapeutic factors in group counseling: The role of interpersonal style and stage of group development. Small Group Behavior, 19, 452-468. 


\section{SOCIAL SUPPORT AND PROBLEM GAMBLING}

Marlatt, G. A., \& Donovan, D. M. (2008). Relapse prevention: Maintenance strategies in the treatment of addictive behaviors. New York: Guilford Press.

Marlatt, G. A., \& George, W. H. (1984). Relapse prevention: Introduction and overview of the model. Addiction, 79, 261-273.

Marlatt, G. A., \& Gordon, J. R. (1985). Relapse prevention: Maintenance strategies in the treatment of addictive behaviors. New York: Guilford Press.

Marotta, J., Bahan, M., Reynolds, A., Vander Linden, M., \& Whyte, K. (2014). 2013 National Survey of Problem Gambling Services. Washington DC: National Council on Problem Gambling.

McCrady, B. S. (2004). To have but one true friend: implications for practice of research on alcohol use disorders and social network. Psychology of Addictive Behaviors, 18, 113-121.

Miller, P. M. (Ed.). (2013). Interventions for addiction: Comprehensive addictive behaviors and disorders (Vol. 3). San Diego, CA: Academic Press.

Moos, R. H. (2007). Theory-based active ingredients of effective treatments for substance use disorders. Drug and Alcohol Dependence, 88, 109-121.

Oei, T. P., \& Gordon, L. M. (2008). Psychosocial factors related to gambling abstinence and relapse in members of gamblers anonymous. Journal of Gambling Studies, 24, 91-105.

Orford, J. (2010). An unsafe bet?: The dangerous rise of gambling and the debate we should be having. Chichester: Wiley.

Orford, J., Wardle, H., \& Griffiths, M. (2013). What proportion of gambling is problem gambling? Estimates from the 2010 British Gambling Prevalence Survey. International Gambling Studies, 13, 4-18. 


\section{SOCIAL SUPPORT AND PROBLEM GAMBLING}

Pagano, M. E., Friend, K. B., Tonigan, J. S., \& Stout, R. L. (2004). Helping other alcoholics in Alcoholics Anonymous and drinking outcomes: Findings from Project MATCH. Journal of Studies on Alcohol, 65, 766-773.

Petry, N. M. (2005). Pathological gambling: Etiology, comorbidity, and treatment. Washington, DC: American Psychological Association.

Petry, N. M. (2007). Testing three paths to improvement: Cognitive-behavioral therapy, self-directed workbook and Gamblers Anonymous. In Roads to Recovery from Gambling Addiction (pp. 14-16). Washington, DC: National Center for Responsible Gaming.

Petry, N. M., Litt, M. D., Kadden, R., \& Ledgerwood, D. M. (2007). Do coping skills mediate the relationship between cognitive-behavioral therapy and reductions in gambling in pathological gamblers? Addiction, 102, 1280-1291.

Reilly, C., \& Shaffer, H.J. (2007). Roads to recovery from gambling addiction. In Roads to Recovery from Gambling Addiction (pp. 2-5). Washington, DC: National Center for Responsible Gaming.

Riessman, F. (1976). How does self-help work? Social Policy, 7, 41-45.

Robinson, F. F. (2012. March). Help-giving as a factor in perceived group helpfulness and member satisfaction in small counseling groups. Paper presented at the American Counseling Association Conference, San Francisco, CA.

Rodriguez-Monguio, R., Errea, M., \& Volberg, R. (2017). Comorbid pathological gambling, mental health, and substance use disorders: Health-care services provision by clinician specialty. Journal of Behavioral Addictions, 6, 406-415.

Sani, F., Magrin Elena, M., Scrignaro, M., \& McCollum, R. (2010). In-group identification mediates the effects of subjective in-group status on mental health. British Journal of Social Psychology, 49, 883-893. 


\section{SOCIAL SUPPORT AND PROBLEM GAMBLING}

Sani, F., Wakefield, J. R., Herrera, M., \& Zeybek, A. (2017). On the association clinical individuals: Evidence from Cypriot and Spanish students. Journal of Social and Clinical Psychology, 36, 396-418.

Schuler, A., Ferentzy, P., Turner, N. E., Skinner, W., McIsaac, K. E., Ziegler, C. P. \& Matheson, F. I. (2016). Gamblers Anonymous as a Recovery Pathway: A Scoping Review. Journal of Gambling Studies, 32, 1261-1278.

Sheeren, M. (1988). The relationship between relapse and involvement in alcoholics anonymous. Journal of Studies on Alcohol, 49, 104-106.

Steffens, N. K., Jetten, J., Haslam, C., Cruwys, T., \& Haslam, S. A. (2016). Multiple social identities enhance health post-retirement because they are a basis for giving social support. Frontiers in Psychology, 7, 1519.

Stephens, R. S., Wertz, J. S., \& Roffman, R. A. (1995). Self-efficacy and marijuana cessation: A construct validity analysis. Journal of Consulting and Clinical Psychology, 63, 1022-1031.

Swartzman, S., Sani, F., \& Munro, A. (2016). The role of social support, family identification, and family constraints in predicting post-traumatic stress after cancer. Psycho-Oncology, 26, 1330-1335.

Tajfel, H., \& Turner, J. C. (1979). An integrative theory of intergroup conflict. In W. G. Austin \& S. Worchel (eds.), The social psychology of intergroup relations (pp. 33-47). Monterey, CA: Brookes/Cole.

Toneatto, T. (2008). Reliability and validity of the gamblers anonymous twenty questions. Journal of Psychopathology and Behavioral Assessment, 30, 71-78.

Weinstein, N., \& Ryan, R. M. (2010). When helping helps: Autonomous motivation for prosocial behavior and its influence on well-being for the helper and recipient. Journal of Personality and Social Psychology, 98, 222-244. 


\section{SOCIAL SUPPORT AND PROBLEM GAMBLING}

Yalom, I. D., \& Leszcz, M. (2005). The theory and practice of group psychotherapy (5th ed.). New York: Basic Books.

Zemore, S. E., Kaskutas, L. A., \& Ammon, L. N. (2004). In 12-step groups, helping helps the helper. Addiction, 99, 1015-1023.

Zemore, S. E., \& Pagano, M. E. (2008). Kickbacks from helping others: Health and recovery. Recent Developments in Alcoholism, 18, 141-166.

Zimet, G. D., Dahlem, N. W., Zimet, S. G., \& Farley, G. K. (1988). The multidimensional scale of perceived social support. Journal of Personality Assessment, 52, 30-41.

Zimet, G. D., Powell, S. S., Farley, G. K., Werkman, S., \& Berkoff, K. A. (1990). Psychometric characteristics of the multidimensional scale of perceived social support. Journal of Personality Assessment, 55, 610-617. 


\section{SOCIAL SUPPORT AND PROBLEM GAMBLING}

\section{Footnotes}

1 'Open' in the present context means that meetings are open to anyone (e.g., new members, friends and family, health professionals, support workers). However, the meetings at the GA fellowship where data-collection occurred were typically attended by GA members only.

${ }^{2}$ High correlations among predictor/mediator variables can lead to problems of multicollinearity which can identified in the variance inflation factors (VIFs). A VIF value greater than 10 indicates problematic multicollinearity (Cohen, Cohen, West, \& Aiken, 2003). All VIFs in the current dataset were $\leq 2.12$ indicating an absence of problematic multicollinearity.

${ }^{3}$ We conducted all analyses with and without covariates and the results were almost identical.

${ }^{4}$ When support received was the only mediator in the model the indirect path from group identification to abstinence self-efficacy through support received was significant, $P E=.21, S E=.11, B C C I: L L=.059, U L=.508$, whereas the indirect path from group identification to perceived risk was not, $P E=-.15, S E=.10, B C C I$ : $L L=-.388, U L=.011$. 


\section{SOCIAL SUPPORT AND PROBLEM GAMBLING}

Table 1. Means, standard deviations and correlations.

\begin{tabular}{lccccccc}
\hline & $M$ & $S D$ & 1 & 2 & 3 & 4 & 5 \\
\hline 1. Recovery group identification & 4.41 & 1.62 & - & .56 & .68 & .73 & -.59 \\
2. Support received & 4.26 & 0.66 & & - & .64 & .59 & -.48 \\
3. Support provided & 3.93 & 0.99 & & - & .79 & -.64 \\
4. Abstinence self-efficacy & 4.89 & 1.66 & & & - & -.73 \\
5. Perceived risk & 3.57 & 2.56 & & & & - \\
\hline
\end{tabular}

Note. Recovery group identification and abstinence self-efficacy scores can range from 1 to 7; support received and support provided scores can range from 1 to 5; perceived risk scores can range from 1 to 10. All correlations are significant at $p<$ .001 . 
SOCIAL SUPPORT AND PROBLEM GAMBLING

\section{Figure caption}

Figure 1. Total, direct, and indirect effects of recovery group identification on abstinence self-efficacy and perceived risk through support received and support provided.

Note. $c=$ total effect; $c=$ direct effect. ${ }^{*} p<.05 .{ }^{*} p \leq .01 .{ }^{* * *} \mathrm{p}<.001,{ }^{\dagger} \mathrm{p}=.07$ 

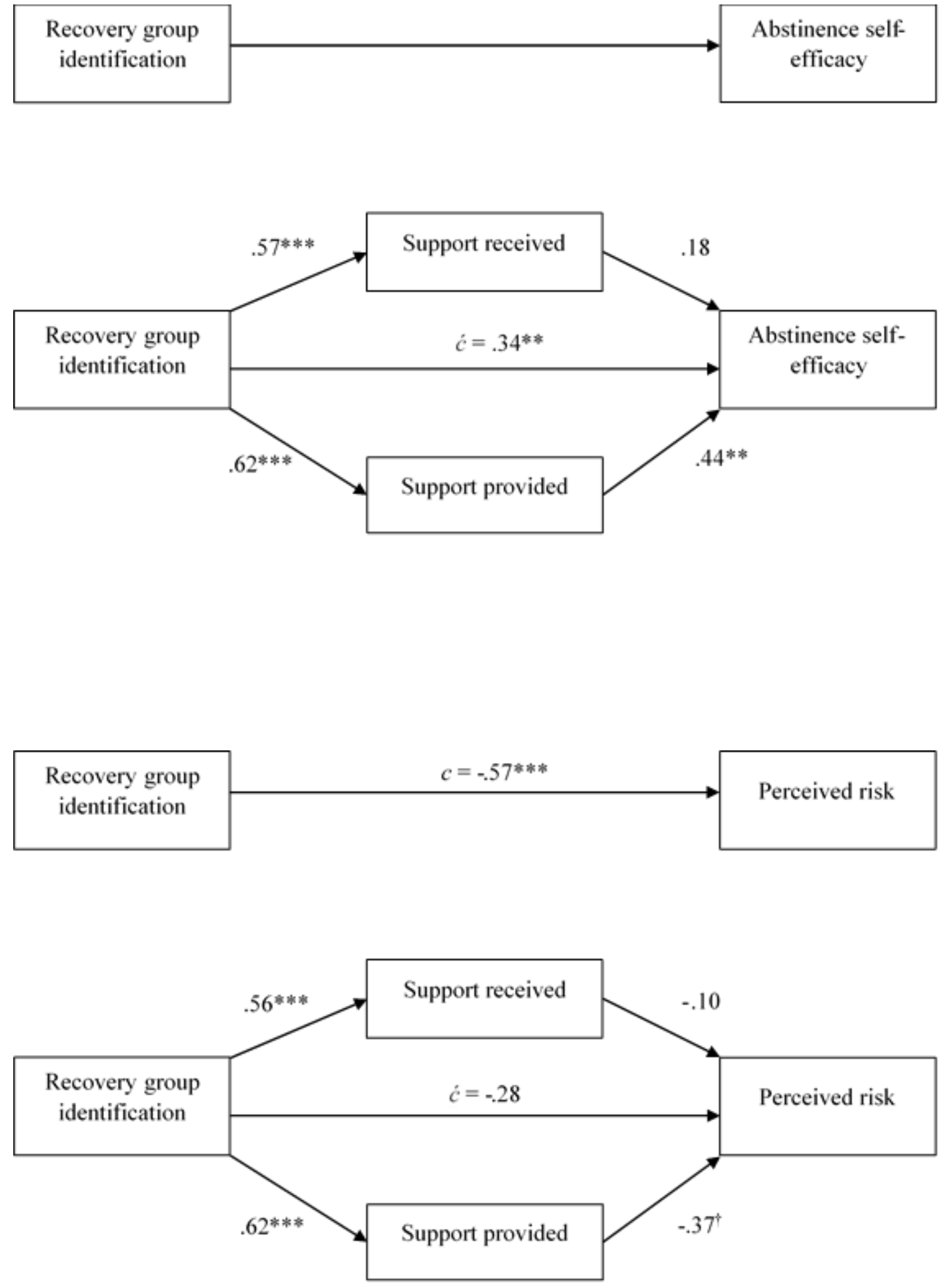